THURSDAY, MAY 8, 1884

\section{A PLEA FOR A NATIONAL MARINE ZOOLOGICAL SURVEY}

$W^{\mathrm{H}}$

HILST the influential meeting recently held at the Royal Society, for the purpose of founding a Society for the Biological Investigation of the British Coast, is still in the minds of naturalists, the present occasion is a fitting opportunity for the expression of opinions respecting the scope and aims of such an undertaking, as well as to suggest in what way zoological investigation in general may be more systematically directed than has hitherto been the case in this country.

The primary object of the newly-formed Society, as indicated in the resolutions passed at the preliminary meeting, is the establishment of a zoological station. This of itself is an important step in the right direction; and though much will depend on the thorough organisation and efficient management of the station, the hearty thanks of naturalists are already due to Prof. Ray Lankester for the energy and perseverance with which he has brought this desideratum within possible attainment. The establishment of a zoological station, however, or even of a number of stations at different parts of our seaboard, is not the only thing wanted. Neither should the maintenance of a single biological laboratory be the only aim of such a Society as the one proposed. Indeed it may be seriously questioned whether a Society is the best, or even a necessary, piece of machinery for the maintenance of a zoological station at all, excepting solely as a subscribing body, and even in this capacity its efficiency may prove inadequate. It is therefore to be hoped that the new Society will realise that there are broader and more extensive claims which zoology has a right to make in a country so peculiarly placed as Britain.

Few will deny that, notwithstanding the impetus given to the study of zoology during the last quarter of a century by the theory of evolution and the revelations of embryology, this branch of science appears in many respects to have been more backward than several of the kindred sister sciences in revising methods of investigation in accordance with the spirit of the age. Biology and morphology have of course made advances whose importance cannot be over-estimated ; but it would seem that Zoology-in the wider sense-might well take a leaf out of the book of her much younger sister, Geology. Years ago, quite in the infancy of that science, national geology was placed upon a systematic basis by the establishment of the Geological Survey. The reason of that step is perhaps not far to seek. It stood mainly upon utilitarian grounds. The geologist was able to show that a knowledge of his science directly concerned the mineral wealth of the country, and that he offered as as it were the key to the then secret storehouses of coal, ores, and water, which were unmistakable synonymous terms for national wealth, advancement, and prosperity. It is quite unnecessary in the present place to do more than refer incidentally to the admirable manner in which the Geological Survey has fulfilled, and is still fulfilling, the purpose of its being. While constantly keeping in view the industrial applications of geology, it has at the same time never lost VoL. Xxx.-NO. 758 sight of the strictly scientific problems which the geological structure of the country presents in such abundance. Its success in both these departments may well point the argument that the zoologist has an equal share, and an equal power to assist, in the nation's welfare, besides possessing his own ample domain in science.

The insular position of this country naturally causes the sea fisheries and all that pertains thereto to be an important factor from a national and pecuniary point of view. The food, the habitat, the cultivation, the development, the enemies, and the diseases of fish all lie within the province of the zoologist; and it is to him alone that we can come for information on these questions, whereon the prosperity of our national fisheries depends, just as it is to the geologist that we go for direction as to the acquirement of the coal and ores that lie treasured beneath our feet, or as to the sources and quality of the water required for the supply of towns. On these grounds national marine zoology may claim an equally systematic method of investigation and an equal recognition as an important handmaiden to national wealth. Patriotism, as well as the desire for the advancement of human knowledge, would therefore urge with all possible earnestness the establishment of a national Marine Zoological and Physical Survey, whereby the fauna and the conditions of every portion of our coast should be carefully investigated. Apart from the unquestionable advantages that would thus be afforded to our fisheries, it is not too much to promise that by this means a greater amount of light would be thrown upon the life-histories of marine organisms, upon the variations of species, and the conditions upon which these depend, together with the solution of a greater number of important zoological problems than we could otherwise ever hope to attain. From a geological point of view, also, it is most desirable to have a better knowledge of the deposits now forming around our coasts. Other countries have already recognised these claims, and the fruition of their foresight is too well known to naturalists to need recapitulation here.

Such a scheme as the present naturally demands national encouragement and Government support. Many will of course say that the British Government is too much hampered and proverbially backward in assisting scientific projects to undertake what is here briefly indicated. May not, however, the want of success in obtaining assistance from Government be found to lie too frequently in the imperfect and partial manner in which application is made? Ministers and members of Government are too frequently "asked" in a private, unofficial manner whether support might probably be obtained for such-andsuch an object; and should this happen to be one with which they are little conversant, it is only natural that the answer should frequently be unsatisfactory.

The establishment of a systematic and permanent Zoological Survey has, from its direct relation with a great national source of wealth, apart from its equally important scientific bearings, a logical claim which cannot be gainsaid; and it is scarcely to be supposed that a properly organised application would fail to be favourably received by the Government. In the event, however, of the prayer of such an application being rejected, the onus of neglecting an important British industry would obviously then rest on the shoulders of the Government; and scientific 
men would at least have done their duty in urging its claims and pointing out whereby it might be protected and augmented. It unfortunately happens that up to the present time scientific men have brought no definite scheme or proposition of this kind directly before Government; and the onus of neglect may consequently in a certain sense be said to rest now at their door.

The honour of removing this responsibility lies directly within the scope of the newly-formed Society for Biological Investigation; for naturally no other body of men could more readily put themselves into communication with the various kindred societies throughout the kingdom, and thus obtain a unison of views upon this important subject. The next step would be to elect an influential representative deputation from the Society to wait upon the Prime Minister for the purpose of urging the appointment of a Parliamentary Commission to inquire exhaustively into the various subjects pertaining to a Zoological Survey.

THE ELECTRTCAL CONGRESS OF PARIS, I 884 THE first Congress of 1881 has borne good fruit. It has not only brought about an approchement between electricians of all countries, but it has led to the adoption of an international system of measurement which will be in universal use. It is satisfactory to find that there are questions which can be amicably settled internationally. The Congress was divided into three Commissions which dealt with (I) electrical units, (2) atmospheric electricity and earth-currents, (3) standard of light. 'The first Commission virtually dealt with the length of a column of mercury of one square millimetre section which represented the ohm-it having been decided at the Congress of 1881 that this should be the unit of resistance. Many physicists had been working on this in different countries and on different methods. M. Mascart grouped the results in the following useful table:-

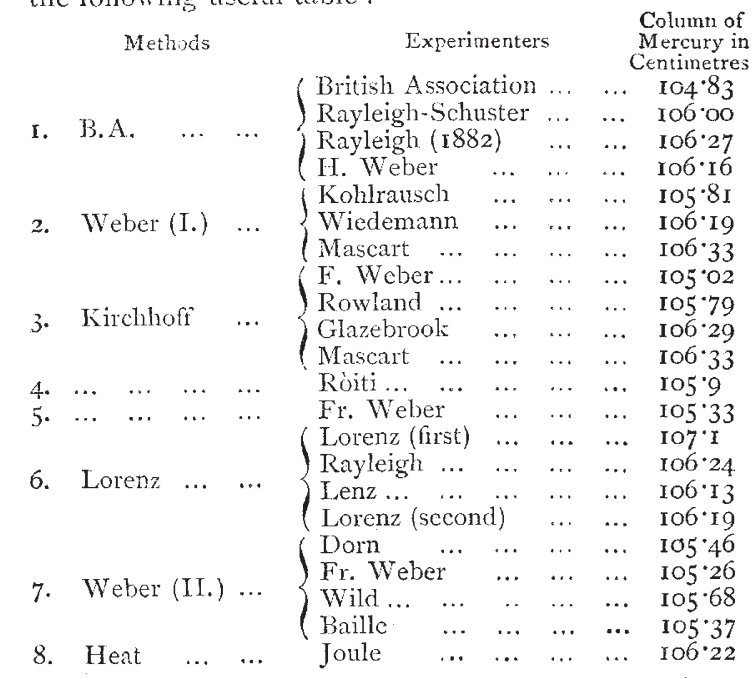

From this it appears that the figures obtaincd by the different methods were-

$\begin{array}{lllllll}\text { B. } . . & \ldots & \ldots & \ldots & \ldots & \ldots & \text { I06.21 } \\ \text { Weber's I. } \ldots & \ldots & \ldots & \ldots & \ldots & \text { I06.14 } \\ \text { Kirchhoff's } \ldots & \ldots & \ldots & \ldots & \ldots & \text { I05.93 } \\ \text { Lorenz } & \ldots & \ldots & \ldots & \ldots & \ldots & \text { I06.19 } \\ \text { Weber's II. } & \ldots & \ldots & \ldots & \ldots & \text { I05.47 } \\ \text { Joule ... } & \ldots & \ldots & \ldots & \ldots & \ldots & \text { 106.22 }\end{array}$

The mean of which was 106.02 , but 106 was taken as a round figure sufficiently near the truth for all practical and useful purposes. Hence the Congress decided that "the legal ohm should be the resistance of a column of mercury of one square millimetre section and of $106 \mathrm{~cm}$. of length at the temperature of freezing," and a resolution was passed desiring the French Government to transmit this resolution to the different Governments, with a view of making its adoption international. It was decided that primary standards should be constructed in mercury, but that secondary coils should be made of solid alloys, which should be frequently compared among themselves and with the primary standard.

It was resolved that the ampère should be exactly $1 \mathrm{O}^{-1}$ C.G.S. electromagnetic unit of current, and that the volt should be the elcctromotive force which maintained an ampere in a conductor whose resistance was the new ohm.

We can now congratulate ourselves upon having a scientific system of electrical units independent of any particular instruments or of any particular process. It is not absolutely exact. That is, the new ohm is not $10^{9}$ C.G.S. units, but it is the nearest approach to it that can be practically attained. It will probably be known as the Congress ohm, to distinguish it from the true ohm ( $10^{9}$ C.G.S.) or the B.A. ohm of 1864 .

One subject of regret is that Prof. Rowland's measurements in Baltimore are not completed, and will probably not be ready before the end of the year. The United States Congress voted a large sum of money to enable this to be done. He is using a Planté secondary battery and employing three methods, viz. Kirchhoff's, Joule's, and Lorenz's. His well-known experimental skill has given much interest to this investigation of Rowland's.

The second Commission dealt with atmospheric electricity and earth-currents, and recommended that it was desirable to send each year to the Bureau International des Administrations 'Télégraphiques in Berne the reports that were collected in the different countries, so that they might be distributed to the different Governments.

The third Commission dealt with the standard of light, and it was decided, not without considerable opposition, that the unit for each simple light should be the quantity of light of the same kind emitted in a normal direction by a square centimetre of surface of fused platinum at the temperature of solidification, and that the practical unit of white light should be the total quantity of light emitted normally by the same source. This is a very unsatisfactory standard. It was accepted because there was virtually none other before. But it was obtained by only one observer (M. Violle) ; it is not portable; it is not even reproducible except at great expense, and it is so eminently impracticable that it is scarcely likely to be generally adopted. It is to be regretted that the British Association Committee on a Standard of White Light has not yet finished its work, but we may hope that at Montreal Capt. Abney will be able to give some results which will give us a better and more practical standard.

There was a universal consensus of opinion that the Congress had faithfully and earnestly done its work, and that the success of its labours and the rapidity of its action was due to the energy and ability of M. Cochery, the Minister of Posts and Telegraphs. Our English representatives were Sir William Thomson, Capt. Abney, 